\title{
DEPRESSION, ATTENTION DEFICIT HYPERACTIVITY DISORDER (ADHD) AND RISKY SEXUAL BEHAVIOUR AS PREDICTORS OF SUBSTANCE USE AMONG WOMEN IN SEX WORK (WSW)
}

\author{
Kasthuri Pandiyan', Shankar Kumar ${ }^{2}$
}

${ }_{1}^{1}$ Associate Professor, Department of Psychiatry, MVJ Medical College and Research Hospital, Hoskote, Bangalore, Karnataka. ${ }^{2}$ Assistant Professor, Department of Psychiatry, Bangalore Medical College and Research Hospital, Bangalore, Karnataka.

\section{ABSTRACT}

\section{BACKGROUND}

There is a substantial burden of substance use among WSW. Substance use in WSW leads to higher risky sexual behaviours and risk of sexually transmitted infections. This risk also is seen with comorbid depression and ADHD in this population. Thus, this study was conducted to study the factors predicting substance use among WSW with depression, ADHD and risky sexual behaviour.

\section{MATERIALS AND METHODS}

246 consenting participants took part in the study after informed consent and Ethical Committee approval. They were administered a sociodemographic questionnaire, audit for alcohol use severity, ASRS for ADHD assessment and HIV Risk Behaviour Scale for risky sexual behaviour. Statistical analysis was done using SPSS V 19.

\section{RESULTS}

Those with substance use had higher income level, lower years of education than those without substance use ( $p=0.03$ and 0.05$)$. Those with substance use had higher risky sexual behaviours than those without substance use $(p=0.03)$. They had inconsistent condom use, more than 5 partners in a single day, group sex which was more than those without substance use. Those with substance use had higher prevalence of risky sexual behaviour, ADHD and depression $(p=0.001)$. When logistic regression was used, we found that there were statistically significant odds ( $\mathrm{OR}=1.26$ and 2.45) of predicting substance use using depression and risky sexual behaviour scores, but not ADHD.

\section{CONCLUSION}

Substance use is highly prevalent among WSM which is associated with depression, risky sexual behaviours and ADHD. Those with depression had higher odds of having substance use. Thus, it is important to screen for these comorbidities and design interventions for the same which would reduce medical and psychological morbidity in this population.

\section{KEYWORDS}

Female Sex Workers, Risk Taking Sexual Behaviour, Substance Use.

HOW TO CITE THIS ARTICLE: Pandiyan K, Kumar S. Depression, attention deficit hyperactivity disorder (ADHD) and risky sexual behaviour as predictors of substance use among women in sex work (WSW). J. Evolution Med. Dent. Sci. 2018;7(16):1966-1969, DOI: $10.14260 /$ jemds/2018/442

\section{BACKGROUND}

In recent years, researchers have begun to explore the intersection of alcohol or drug use and sexual "risk behaviour" activities that put people at increased risk for STDs, unintended pregnancy and sexual violence. The global burden of substance use is substantial, accounting for $8.9 \%$ of productive life lost annually due to disability and premature mortality as measured in disability-adjusted life-years (DALYs).

A cross-sectional survey in Adama City, Ethiopia found that a high prevalence of work-related violence (59\%) and alcohol abuse among WSW (51\%),(1) (Alem et al, 2006). The overlap between illicit drug use and female sex work has been identified as an important factor responsible for rising HIV prevalence among FSWs in several North-Eastern states of India.(2)

'Financial or Other Competing Interest': None.

Submission 10-03-2018, Peer Review 03-04-2018,

Acceptance 09-04-2018, Published 16-04-2018.

Corresponding Author:

Dr. Shankar Kumar,

Assistant Professor,

BMCRI, Bangalore, Karnataka.

E-mail: shankarkjs@gmail.com

DOI: $10.14260 /$ jemds $/ 2018 / 442$

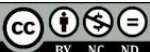

Sex work is associated with a host of psychosocial vulnerabilities including exposure to childhood physical abuse, childhood sexual abuse, interpersonal violence in adulthood and substance uses.(3) Vanwesenbeeck showed that in a sample of 96 WSWs the prevalence of depression was $73 \%$, post-traumatic stress disorder was $30 \%$ when compared to those among female nurses being 53\%.(4) Studies have shown depression and stress to be associated with higher levels of risky sexual behaviour.(5) Substance use contributes to a higher morbidity with depression(6) and ADHD also has recent evidence to increase risky sexual behaviour in WSW.(7) However, studies have not consistently predicted the contribution of these risk factors individually to substance use disorders. Thus, this study was conducted in this background.

\section{Aims and Objectives}

To study the patterns of substances used and association between substance use and depression, ADHD and risky sexual behaviours in this population of WSW.

\section{MATERIALS AND METHODS Study Sample}

Participants were recruited from a special clinic catering to mental health needs of WSW in Department of Psychiatry, 
Victoria Hospital. Sample size was chosen as convenience. It was a cross-sectional study. Patients to this clinic are brought by counsellors from voluntary agencies, which deal with preventing HIV/AIDS and STIs among WSW and to improve their overall quality of life $(n=246)$. All the participants were asked to register their understanding and consent to participate in the study by oral consent signed in the form by an impartial witness. The approval for the study was taken from the Institutional Ethical Committee (IEC).

246 consenting participants took part in the study. We hypothesised that substance use in WSW should be predicted by depression, risky sexual behaviours and ADHD severity. We also wanted to study the patterns of substances used, association between substance use and depression, ADHD and risky sexual behaviours in this population.

Interviews were conducted at Victoria Hospital, Bangalore. The interview was conducted by the principal investigator in a place, which ensured visual and auditory privacy.

The questionnaires used for the study was administered by the psychiatrist, clinical psychologist, social worker and postgraduate students in the special clinic catering to mental health needs of WSW.

A semi-structured interview was used to elicit the following details- Sociodemographic Data: Age, marital status and years of marriage, educational status, employment status, income, living status and occupational status. Various risky sexual behaviours were documented. Patterns of substances used were also noted-

1. Adult ADHD Self-Report Scale (ASRS) was used to screen for ADHD symptoms. The ASRS was developed by the World Health Organisation and the short form of the screener consists of a checklist of six questions regarding symptoms of ADHD based on the diagnostic criteria of DSM-IV-TR. Each item requires respondents to rate on a five-point response scale from "never" [0] to "very often," [4] how frequently a particular symptom of ADHD occurred over the past six months. A cut-off of 14 for the first 6 items of the screener was used as described by Kessler, 2007.(8) In addition as described by Kessler, subjects who scored a total of 9 or more of the shaded boxes of the whole scale were only considered as having symptoms of ADHD.

2. Wender Utah Rating Scale (WURS) was used to assess presence of childhood ADHD symptoms. A diagnosis of ADHD was made if an individual scored over a cut-off of 24 on the ASRS with a WURS score of 46 or above indicating presence of ADHD symptoms in childhood in those individuals who scored above the cut-off on ASRS.

3. HIV Risk Behaviour Scale (HRBS) was used to screen for high-risk sexual behaviour.(9)

4. MINI neuropsychiatric interview was used to screen for presence of psychiatric comorbidities. ${ }^{(10)}$

5. Beck's Depression inventory 2 (self-rated) was used to assess the severity of depression when present.(11)

Statistical analysis was performed using SPSS V 19 software. T-test was used to compare various continuous variables such as BDI, ASRS and HRBS scores between those with and without substance use. Pearson correlation coefficient was used to assess relationship between substance use severity and BDI, ASRS and HRBS scores.
Multiple logistic regression was used to predict risk of substance use using ADHD, depression and risky sexual behaviour scores as predictor variables. Pearson correlation coefficient was used, t-test, Fisher's Exact test, Spearman's correlations are used. (Unpaired t-test) are expressed as Mean \pm Standard deviation.

\section{RESULTS}

\section{Sociodemographic Profile}

\begin{tabular}{|c|c|c|}
\hline & $\begin{array}{c}\text { Substance } \\
\text { Use (Mean, SD) } \\
\text { (n=212) }\end{array}$ & $\begin{array}{c}\text { No Substance } \\
\text { Use (Mean, SD) } \\
\text { (n=42) }\end{array}$ \\
\hline Age (yrs.) & $30.2(5.34)$ & $34.3(6.54)$ \\
\hline Income (Rupees) & $15,456.8$ & $12,324.5$ \\
& $(4521.3)$ & $(2341.4)$ \\
\hline Education (yrs.) & $3.61(1.34)$ & $4.32(1.36)$ \\
\hline Years of Marriage & $10.34(3.45)$ & $11.23(4.34)$ \\
\hline
\end{tabular}

\begin{tabular}{|c|c|c|c|}
\hline & & $\begin{array}{c}\text { Substance } \\
\text { Use } \\
\text { (n=212) }\end{array}$ & $\begin{array}{c}\text { No } \\
\text { Substance } \\
\text { Use (n=42) }\end{array}$ \\
\hline \multirow{3}{*}{ Marital Status } & Married & 183 & 23 \\
\cline { 2 - 4 } & Widowed & 14 & 7 \\
\cline { 2 - 4 } Living Status & Separated & 15 & 12 \\
\cline { 2 - 4 } & Nuclear & 143 & 26 \\
\cline { 2 - 4 } & Joint Family & 19 & 9 \\
\cline { 2 - 4 } Occupation & Living Alone & 50 & 7 \\
\cline { 2 - 4 } & Homemaker & 112 & 20 \\
\cline { 2 - 4 } & Garments & 30 & 5 \\
\cline { 2 - 4 } & Cook/Maid & 70 & 17 \\
\hline
\end{tabular}

\section{Risky Sexual Behaviours in the Sample}

\begin{tabular}{|c|c|c|}
\hline & $\begin{array}{c}\text { Substance Use } \\
(\mathbf{n = 2 1 2})\end{array}$ & $\begin{array}{c}\text { No Substance } \\
\text { Use (n=42) }\end{array}$ \\
\hline 1. Consistent Condom Use & 32 & 31 \\
\hline 2. More than 5 Partners & 34 & 07 \\
\hline 3. Group Sex & 16 & 08 \\
\hline $\begin{array}{c}\text { 4. Injection Drug use } \\
\text { before Sex }\end{array}$ & 07 & 04 \\
\hline 5. Alcohol Use before Sex & 44 & 15 \\
\hline
\end{tabular}

Note- Those with substance use had higher prevalence of risky sexual behaviours such as less consistent condom use, more than 5 partners in a day, group sex.

\section{Patterns of Substances Used}

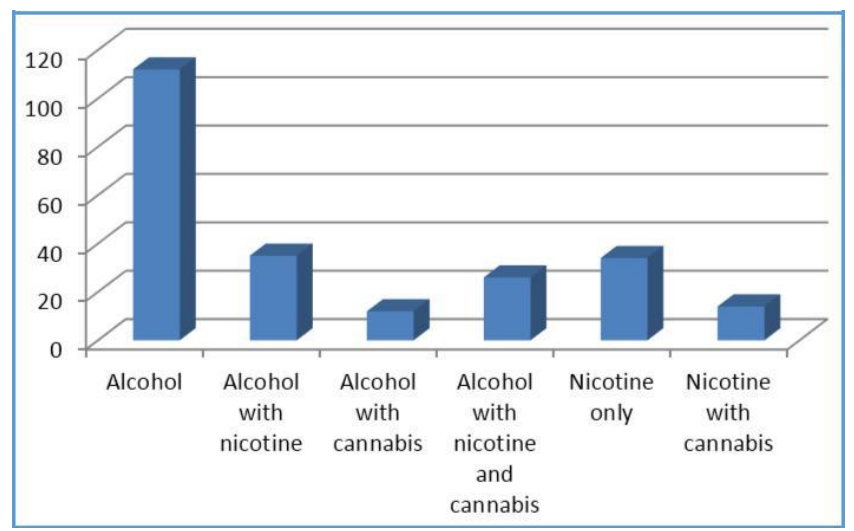


4. Comparison of Scores on Depression, Risky Sexual Behaviour, ADHD between those With and Without Substance Use

\begin{tabular}{|c|c|c|c|c|}
\hline & $\begin{array}{c}\text { Substance } \\
\text { Use }\end{array}$ & $\begin{array}{c}\text { No } \\
\text { Substance } \\
\text { Use }\end{array}$ & $\begin{array}{c}\text { T } \\
\text { value }\end{array}$ & P value \\
\hline $\begin{array}{c}\text { Depression (BDI) } \\
\text { Risky Sexual }\end{array}$ & 29.87 & 26.32 & 1.80 & 0.08 \\
$\begin{array}{c}\text { Behaviour (HRBS) } \\
\text { ASRS (ADHD) }\end{array}$ & 18.65 & 12.55 & 3.21 & $0.001^{* *}$ \\
AST.08 & 18.66 & 5.32 & $0.001^{* *}$ \\
\hline
\end{tabular}

\section{Note}

Those with substance use had higher risky sexual behaviour, ADHD scores than those without substance use.

5. Correlation between Alcohol use Severity with Depression, Risky Sexual Behaviour and ADHD

\begin{tabular}{|c|c|c|}
\hline Alcohol Use Severity VS & R value & P value \\
\hline Depression & 0.48 & $0.03^{*}$ \\
\hline Risky Sexual Behaviour & 0.54 & $0.02^{*}$ \\
\hline ADHD & 0.42 & $0.04^{*}$ \\
\hline
\end{tabular}

6. Multiple Logistic Regression to Predict Risk of Substance use with Depression, Risky Sexual Behaviour and ADHD as Predictor Variables

\begin{tabular}{|c|c|c|c|c|c|}
\hline Variables & Coeff B & $\begin{array}{c}\text { Std. } \\
\text { Error }\end{array}$ & P value & $\begin{array}{c}\text { Odds } \\
\text { Ratio }\end{array}$ & 95\% CI \\
\hline Depression & 0.38 & 0.04 & $0.04^{*}$ & 1.26 & $1.03-1.68$ \\
\hline Risky Sex & 0.49 & 0.08 & $0.01^{*}$ & 2.45 & $1.23-3.55$ \\
\hline ADHD & 0.29 & 0.03 & 0.06 & 1.34 & $0.94-1.67$ \\
\hline \multicolumn{6}{|c|}{ Overall Model Fit- Chi-Square $=17.665, \mathrm{p}=0.003^{*}$} \\
\hline
\end{tabular}

\section{Note}

Substance use risk could be predicted by risky sexual behaviour and depression in this sample, but not ADHD scores.

\section{DISCUSSION}

This was a cross-sectional study, which aimed to study the factors predicting substance use among depression, ADHD and risky sexual behaviour in WSWs in a Tertiary Care Centre with presence of a Special Clinic catering to mental health needs of this population.

\section{Sociodemographic Factors}

Those with substance use had higher income level, lower years of education than those without substance use. This could be probably because of higher risky sexual behaviour in those with substance use,(7) which contributed to higher income as a result of sex work. Lower educational attainment in those with substance use could be because of associated psychiatric comorbidity and psychosocial adversities.

Those with substance use were more likely to be married, probably which could be explained by cultural factors, wherein those with psychological morbidity have higher likelihood to be married at an early age in this geographical background.

\section{Risky Sexual Behaviours}

Those with substance use had higher risky sexual behaviours than those without substance use. They had inconsistent condom use, more than 5 partners in a single day, group sex which was more than those without substance use. Higher risky sexual behaviours in those with substance use can be attributed to greater psychiatric comorbidity in this population such as depression, $(5,7)$ perceived stress, ADHD.

\section{Psychiatric Comorbidity and Predicting Substance Use}

Those with substance use had higher prevalence of risky sexual behaviour, ADHD and depression. This is in concordance with existing literature, which could be explained by common biological predisposition for the same as well as higher prevalence of psychosocial adversities in this population.(12)

There was a significant correlation which was also observed between alcohol use severity and depression, risky sexual behaviour and ADHD which can be explained by the above factors.

When logistic regression was used to predict the risk of substance use in this population with depression scores, risky sexual behaviour scores and ADHD scores (which were selected in view of association with substance use severity in correlation), we found that there was a statistically significant odds of predicting substance use using depression and risky sexual behaviour scores but not ADHD. This is in concordance with existing literature, which states that depression and risky sexual behaviour are associated with substance use.(7) Though, ADHD had a good correlation with substance use, it could be mediated by higher depression and risky sexual behaviour levels in those with ADHD.

\section{Limitations}

The study sample comprised of a group, which was referred by various agencies for assessment of mental health status. Thus, the findings may not be generalisable to WSW present in the community at large. HRBS is a reliable tool to assess risk behaviours for HIV; hence, all risky sexual behaviours were not comprehensively evaluated. Severity of other substance use, apart from alcohol were not done as the group was small. It is a cross-sectional study and the findings would be better validated if the group could be followed up with interventions to reduce psychiatric morbidity.

\section{CONCLUSION}

Substance use is highly prevalent among WSM, which is associated with depression, risky sexual behaviours and ADHD. Those with depression had higher odds of having substance use.

Thus, it is important to screen for these comorbidities and design interventions for the same, which would reduce medical and psychological morbidity in this population.

\section{REFERENCES}

[1] Alem A, Kebede D, Mitike G, et al. Unprotected sex, sexually transmitted infections and problem drinking among female sex workers in Ethiopia. Ethiop J Health Dev 2006;20(2):93-8.

[2] Panda S, Bijaya L, Sadhana DN, et al. Interface between drug use and sex work in Manipur. Natl Med J India 2001;14(4):209-11. 


\section{Jemds.com}

[3] Burnette ML, Lucas E, Ilgen M, et al. Prevalence and health correlates of prostitution among patients entering treatment for substance use disorders. Arch Gen Psychiatry 2008;65(3):337-44.

[4] Vanwesenbeeck I. Burnout among female indoor sex workers. Arch Sex Behav 2005;34(6):627-39.

[5] Gilchrist G, Gruer L, Atkinson J. Comparison of drug use and psychiatric morbidity between prostitute and non-prostitute female drug users in Glasgow, Scotland. Addict Behav 2005;30(5):1019-23.

[6] Kelly JA, Murphy DA, Bahr GR, et al. Factors associated with severity of depression and high risk sexual behavior among persons diagnosed with HIV infection. Health Psychol 1993;12(3):215-9.

[7] Pandiyan K, Kumar S, Hongally C. Prevalence of ADHD in women sex workers and other characteristics in OPD of a tertiary care. Journal of Research in Psychiatry and Behavioral Sciences 2015;1(1):21-4.

[8] Kessler RC, Adler L, Ames M, et al. The World Health Organization adult ADHD self-report scale (ASRS): a short screening scale for use in the general population. Psychol Med 2005;35(2):245-56.

\section{Original Research Article}

[9] Darke S, Hall W, Heather N, et al. The reliability and validity of a scale to measure HIV risk-taking behaviour among intravenous drug users. AIDS 1991;5(2):181-5.

[10] Sheehan DV, Lecrubier Y, Sheehan KH, et al. The miniinternational neuropsychiatric interview (M.I.N.I.): the development and validation of a structured diagnostic psychiatric interview for DSM-IV and ICD-10. J Clin Psychiatry 1998;59(Suppl 20):22-33; quiz 34-57.

[11] Steer RA, Ball R, Ranieri WF, et al. Dimensions of the beck depression inventory-II in clinically depressed outpatients. J Clin Psychol 1999;55(1):117-28.

[12] Olvera RL, Bearden CE, Velligan DI, et al. Common genetic influences on depression, alcohol, and substance use disorders in Mexican-American families. Am J Med Genet B Neuropsychiatr Genet 2011;156B(5):561-8. 